production of sleep abnormalities and expression of positive and negative symptoms. These data indicate the need for systematic trials of cholinergic and anticholinergic agents in the treatment of positive and negative symptoms of schizophrenia, respectively.

\section{COVARIANCE OF POSITIVE AND NEGATIVE SYMPTOMS DURING TREATMENT WITH TYPICAL NEUROLEPTICS AND CLOZAPINE}

\author{
Rajiv Tandon,* Saulo CM Ribeiro, Melinda Perez, John \\ F. Greden \\ University of Michigan Schizophrenia Program, Ann Arbor, MI \\ 48109-0120, USA
}

Although poor response to neuroleptics has traditionally been considered a characteristic feature of negative schizophrenic symptoms, several recent studies have documented significant improvement in negative symptoms in schizophrenic patients treated with neuroleptics. The question of whether neuroleptic-induced improvement in negative symptoms is linked to concomitant improvement in positive symptoms or occurs independently of such improvement is unresolved; it is also unclear if this profile is similar during treatment with clozapine and typical neuroleptics. To address these issues, we studied 120 RDC/DSM-III-R schizophrenic inpatients at drug-frec baseline and after 3-4 wecks of treatment with clinically-determined doses of typical neuroleptics. We also studied 40 RDC/DSM-III-R schizophrenic patients before a trial of clozapine and after 4-6 weeks of initiating clozapine treatment. Positive and negative symptoms were assessed by the BPRS "THOT" factor and the SANS sum of global scores, respectively. During treatment with typical neuroleptics, there was significant improvement in both positive symptoms (15.6 \pm 2.9 to $10.2 \pm 3.2)$ and negative symptoms $(12.5 \pm 4.2$ to $8.6 \pm 3.4)$; the change in positive symptoms was highly correlated to the change in negative symptoms $(\mathrm{r}=0.60 ; \mathrm{p}<0.001)$. During treatment with clozapine, both positive symptoms (from $16.0 \pm 3.6$ to $12.4 \pm 3.5$ ) and negative symptoms (from $13.8 \pm 4.5$ to $10.5 \pm 4.1$ ) improved significantly; change in positive symptoms was again significantly correlated to change in negative symptoms ( $r=0.63 ; p<0.01)$. Although there are sample differences between the two groups making comparisons difficult, these data indicate that negative symptoms improve along with positive symptoms in the course of initial neuroleptic treatment, both with typical neuroleptics and clozapine. Clozapine's apparent greater efficacy on negative symptoms may be related to its greater efficacy on positive symptoms (in otherwise treatment-refractory patients) and its lower propensity to cause EPS.

\section{A HIGH CONCENTRATION OF PLASMA INTERLEUKIN-6 IN SCHIZOPHRENIC PATIENTS TREATED WITH NEUROLEPTIC DRUGS}

\author{
J. Wei*, H-M. Xu, G.P. Hemmings \\ Institute of Biological Psychiatry, SAGB, Bangor, Gwynedd LL57 \\ $2 U W, U K$
}

In a previous study, we found a low concentration of plasma interleukin (IL)- $1 \alpha$ in neuroleptic-free patients with schizophrenia. In view of the considerable overlap in the cellular sources and biological activity of IL-1, IL-6 and tumor necrosis factor (TNF), it was thought necessary to examine all three of the relevant cytokines in schizophrenic patients. This study denonstrated that the concentration of plasma IL-6 was significantly higher in the patients taking neuroleptic drugs $(5.95 \pm 1.20 \mathrm{pmol} / \mathrm{L}, \mathrm{n}=32)$ than in those not taking neuroleptic drugs $(4.81 \pm 1.13 \mathrm{pmol} / \mathrm{L}, \mathrm{n}=13$, $\mathrm{p}<0,01$ ), but was not significantly higher than in normal control subjects $(5.04+1.78 \mathrm{pmol} / \mathrm{L}, \mathbf{n}=9, p>0.05)$. Kruskal-Wallis analysis of' variance revealed a significant difference in the concentration of plasma IL-6 among the patients taking neuroleptic drugs, those not taking neurolpetic drugs and normal control subjects $(\mathrm{H}=7.1, \mathrm{df}=2, \mathrm{p}<0.05)$. The increased plasma IL-6 was not related to the clinical state of the patients taking neuroleptic drugs. No significant differences of plasma IL-1 $\beta$ and TNF- $\alpha$ were found between the three groups. These results suggest that neuroleptic treatment may increase only $I L 6$ production, and that the low concentration of plasma IL- $\alpha$ found in our previous study may be peculiar to schizophrenia.

\section{CLINICAL REVIEW OF CLOZAPINE TREATMENT IN A STATE HOSPITAL}

\author{
W. H. Wilson* \\ Department of Psychiatry, Oregon Health Sciences University, \\ Portland, OR 97201-3098, USA
}

We recently reported on a review of the medical records of the first 37 patients to begin clozapine treatment at a state hospital in Oregon. Records were reviewed for the six months before clozapine treatment and six months after. Patients had a long history of schizophrenia and had responded poorly to antipsychotic medication. Clozapine treatment was generally well tolerated, although the rate of seizures $(8 \%)$ was slightly higher than expected. Psychotic symptoms decreased as measured by the Brief Psychiatric Rating Scale, as did symptoms of tardive dyskinesia, as measured by the Abnormal Involuntary Movement Scale. Thirtyfour patients remained hospitalized after six months of treatment. However, indicators of social function (hospital privilege level, community passes, violent episodes, and episodes of seclusion and restraint) all showed that patients improved markedly after receiving clozapine. We will present data extending this analysis to include a six month follow-up of 100 patients, with 68 of the patients followed for eighteen months. 